\title{
Movimiento estudiantil mendocino y genocidio: tratamiento de Los Andes durante los primeros meses del periodo autoritario
}

\author{
Mendoza's student movement and genocide: media treatment of \\ Los Andes during the first months of the authoritarian period
}

María Paula Baigorria Bernal paulabaigorriabernal@gmail.com

http://orcid.org/0000-0001-6691-6597

Facultad de Ciencias Políticas y Sociales;

Universidad Nacional de Cuyo (Argentina)

\section{Resumen}

La dictadura cívico-militar que irrumpió en nuestro país en 1976 se propuso, entre sus principales acciones, llevar a cabo un plan sistemático de persecución y eliminación de sus adversarios/as políticos. Pero esta tarea no se hubiera logrado sin una serie de complicidades civiles y empresariales; el papel de los medios de comunicación, por ejemplo, fue fundamental. En este sentido, este trabajo se propone analizar el tratamiento periodístico realizado por el diario Los Andes sobre el movimiento estudiantil mendocino durante los primeros meses del gobierno de facto. El estudio de la prensa local es abordado desde la teoría del análisis crítico del discurso (ACD) y desde la teoría de las identidades mediáticas.

El objetivo general del estudio es contribuir a generar conocimiento sobre el rol de la prensa mendocina durante el genocidio. En el trabajo se observó cómo el papel de la prensa fue 
fundamental para montar y justificar la acción del aparato represivo. Así, los/as estudiantes universitarios/as (y con ellos la juventud de la época) fueron demonizados, catalogados de subversivos, extremistas, terroristas y enemigos de la Patria, justificando su persecución, desaparición y/o asesinato.

Palabras clave: movimiento estudiantil; genocidio; medios de comunicación; Mendoza.

\section{Abstract}

The civic-military dictatorship that broke into our country in 1976 was proposed, among its main actions, to carry out a systematic plan of persecution and elimination of its political adversaries. But this task would not have been achieved without a series of civil and business complicities; The role of the media, for example, was fundamental. In this sense, this work intends to analyze the journalistic treatment carried out by the Los Andes newspaper about the student movement in Mendoza during the first months of the de facto government. The study of the local press is approached from the theory of critical analysis of discourse (ACD) and from the theory of media identities.

The general objective of the study is to contribute to generate knowledge about the role of the Mendoza press during the genocide. In the work it was observed how the role of the press was fundamental to mount and justify the action of the repressive apparatus. Thus, the university students (and with them the youth of the time) were demonized, classified as subversives, extremists, terrorists and enemies of the Homeland, justifying their persecution, disappearance and / or murder.

Keywords: student movement; genocide; mass media; Mendoza.

El tema desarrollado en el presente trabajo es el tratamiento mediático realizado por el diario Los Andes, sobre el movimiento estudiantil mendocino durante los primeros meses de la última dictadura cívico-militar. Se pondrá especial acento en los y las estudiantes pertenecientes a la Universidad Nacional de Cuyo. El trabajo pertenece a un fragmento de mi tesis de grado titulada: La construcción mediática del movimiento estudiantil mendocino: periodo 1970-1976. Caso diario Los Andes. Si bien allí analizo un periodo que abarca casi seis años, para el presente caso se utilizará el análisis perteneciente al último periodo dictatorial. 
El objetivo general de este trabajo es contribuir a generar conocimiento sobre el rol de la prensa mendocina durante la última dictadura cívico-militar. Los objetivos específicos son: analizar el rol que desempeñó la prensa local en la construcción de identidades públicas del colectivo estudiantil por un lado y respecto a los militares por otro.

Las hipótesis centrales que guiaron esta investigación fueron, por un lado, que la prensa local utilizó el mismo lenguaje que la dictadura, lo que implicó la legitimación del discurso oficial respecto a la lucha contra la subversión y el establecimiento del orden. Por otro, que el diario colaboró en crear un imaginario de desastre y violencia donde el establecimiento del orden debía ser inminente. Los militares debían terminar con los "enemigos del pueblo"; la "subversión estudiantil" estaba entre ellos. El último supuesto sostiene que Los Andes promovió construcciones discursivas en las que se atribuía características negativas a los/as estudiantes, tales se asocian con las palabras subversión, terroristas, apátridos, entre otras. A su vez asoció características y acciones positivas para los integrantes de las Fuerzas Armadas, como por ejemplo atribuirle la tarea de ordenar al país en base a "valores democráticos, cristianos y occidentales".

Para llevar a cabo la investigación se utilizó la metodología cualitativa. La estrategia seleccionada fue la observación documental, un minucioso trabajo hemorográfico, que consistió en la recopilación y el análisis de notas periodísticas de Los Andes, desde el 24 de marzo de 1976 al 31 de diciembre de ese año, haciendo foco en las crónicas que involucraban al movimiento estudiantil. Desde el análisis crítico del discurso, se examinó el tratamiento mediático realizado por la prensa y desde la teoría de las identidades mediáticas, la elaboración de identidades. El análisis se realizó organizando la información a través de una serie de categorías, entendiendo que "Las categorías articulatorias de un discurso son el resultado de la reescritura del contexto social dentro del texto" (Fernández Nadal, 2001: 209). Se trata de las nociones de juventud-estudiantes, participación política, "subversión", orden y fuerzas de seguridad.

Como se dijo, el estudio es abordado desde la teoría del análisis crítico del discurso (ACD) y desde la teoría de las identidades mediáticas. El ACD es "un tipo de investigación analítica sobre el discurso que estudia primariamente el modo en que el abuso del poder social, el dominio y la desigualdad son practicados, reproducidos (...) por los textos y el habla en el contexto social y político" (Van Dijk, 1999: 23). Las identidades mediáticas son identidades colectivas que son objeto de producción y difusión por parte de los medios masivos (Sampedro, 2014). Es decir, son "formas de representación pública presentes en el contenido y los mensajes de los medios de comunicación" (Ibidem: 138). 
El diario Los Andes aparece bajo la gobernación de José Miguel Segura el 20 de octubre de 1883 en la provincia de Mendoza y fue fundado por Adolfo Calle, abogado y político mendocino. Para Rodríguez Agüero (2014) el matutino ha sido históricamente portavoz de los grupos dominantes mendocinos y símbolo del conservadurismo político y cultural. Sostiene además que, al ser el de mayor tirada, ha sido y es un elemento central del sentido común dominante. Este trabajo busca poner en evidencia cómo la práctica periodística se convirtió en una herramienta fundamental para defender, justificar y avalar la represión y las políticas económicas, sociales, culturales y políticas llevadas a cabo por el régimen militar. Estudiar el caso del diario Los Andes permite hacer foco en la prensa local y se convierte en un aporte importante, ya que son escasos los estudios que buscan analizar el rol de la prensa mendocina en el periodo de facto.

\section{0-1973: ejemplo de un proceso que "nunca más" debe suceder}

La represión en las universidades no puede entenderse sin tener presente la gran participación política y organización del movimiento estudiantil (y de las organizaciones en general) durante los años setenta. Probablemente el momento de mayor fuerza política del colectivo analizado puede ubicarse en las luchas contra el llamado limitacionismo, llevadas adelante durante 1970 y 1971; pero sobre todo con el proceso de apertura universitaria que comienza en 1973.

Los años setenta son caracterizados por una fuerte efervescencia política. Esta situación se daba a nivel nacional, regional e internacional. El Mayo francés, la Revolución cubana, la asunción de Salvador Allende en Chile, eran acontecimientos que propiciaban un nuevo clima político. Para Molina Galarza (2014) "estos sucesos hicieron tambalear las certezas ideológicas del mundo occidental, cristiano y capitalista de aquellos años" (p. 89). Este contexto propiciaba los cuestionamientos, el involucramiento político: "Las nuevas camadas que se incorporaban en esos años a la educación universitaria o al ámbito laboral fueron alumbradas por procesos de transformación que apuntaban a la revolución social en gran parte del mundo" (Bravo, 2014: 27).

Puede considerarse a las luchas contra el limitacionismo las luchas pioneras de los años setenta. Traducidas a un lenguaje actual, serían las demandas por el ingreso irrestricto. Por aquella época, los y las estudiantes universitarios reclamaban contra un examen de ingreso que los limitaba, que era sólo accesible a aquellas personas que podían pagar preuniversitarios. Esta restricción se debía a la Ley Universitaria 17.245, que se encontraba en 
vigencia desde 1967 y que, entre sus aspectos fundamentales, fijaba un examen de ingreso (Baigorria, 2014).

Respecto de las luchas contra el limitacionismo, es preciso señalar por los menos dos acontecimientos que sucedieron o se vincularon directamente con nuestra provincia. El primero de ellos se desarrolló durante los primeros meses de 1970. En esa ocasión estudiantes de la Facultad de Ingeniería de la UNCuyo (con sede en San Juan) comenzaron un plan de lucha contra el ingreso de esa facultad. En ese marco, toman el establecimiento quedando el vicedecano y tres docentes dentro de la institución. Dos de los universitarios que encabezaron la medida, César Eguaburu y Rolando Coria, fueron procesados y llevados a juicio en Mendoza. En respaldo de ellos y de su lucha, estudiantes de la provincia se movilizan hasta el lugar donde se llevó a cabo el juicio. Mientras afuera habían cánticos de apoyo y represión, Eguaburu y Coria, eran condenados a un año y un año y medio. De todos modos "La condena quedó en suspenso. Pero quedó muy claro que de no haber mediado la actitud solidaria de los universitarios mendocinos, las condenas hubieran sido más duras" (Vélez, 1999: 102).

El segundo acontecimiento se vincula con las asambleas y tomas de facultades que se inician contra el examen de ingreso de la Facultad de Ciencias Económicas de la UNCuyo, y que luego se traslada al cuestionamiento del ingreso en todas las unidades académicas. En ambos hechos se repiten acciones similares: solidaridad entre el movimiento estudiantil, gran despliegue de las fuerzas de seguridad para reprimir las manifestaciones, encarcelamiento de estudiantes por algunos días y apertura de causas judiciales contra los y las manifestantes.

El respaldo de los/as estudiantes a las demandas y luchas de sus pares dejará de ser un suceso aislado y comenzará a responder a una visión de Universidad:

\footnotetext{
La lucha contra el limitacionismo en que se encuadra esta muestra de solidaridad se basa en el compromiso con un proyecto de universidad que contemplara a todos los sectores sociales, en especial a los trabajadores. Numerosas acciones se vinculan con el reclamo por condiciones académicas que resultaran aptas para quienes, además de estudiar, trabajaran (Bravo, 2014: 37).
}

Con la llegada a la presidencia de Héctor Cámpora en 1973, se hizo cargo del Ministro de Cultura y Educación Jorge Taiana. Juntos encabezarán una serie de acciones que propiciaron la apertura política en las universidades nacionales de todo el país. Dispusieron la intervención de las mismas con el objetivo de la normalización, de poner en vigencia nuevamente la institucionalidad democrática (Molina Galarza, 2014). En la UNCuyo este proceso se lleva adelante con Roberto Carretero como rector y Arturo Roig como secretario académico; juntos 
inician un proceso de reformas político-pedagógicas que no registra antecedentes y que inclusive, en la actualidad, resultan impensadas:

Entre las transformaciones más significativas introducidas por la gestión de Carretero/Roig, se reincorporó a docentes y estudiantes que habían sido suspendidos durante el período dictatorial previo; se aseguró el derecho a la gratuidad de la enseñanza (amenazado a través del cobro de aranceles administrativos) y el derecho al ingreso sin restricciones. Además, se abrieron instancias de crítica y debate acerca de la ley universitaria vigente, se elaboraron aportes para la redacción de una futura ley nacional que la reemplazara y se comenzó a discutir sobre el rol social que la universidad debía cumplir (Molina Galarza, 2014: 94).

En este breve periodo, los/as jóvenes tienen un rol activo en la confección de planes de estudio, en la elección de las autoridades; además llevan adelante juicios académicos (1) a profesores, toma de facultades, entre otras medidas y acciones directas que dan cuenta del dinamismos que logró el colectivo estudiantil (Baigorria, 2014). Sobre este periodo dice Roig:

Esta decisión gubernamental abrió uno de los periodos más ricos y fecundos que se haya vivido en la historia de nuestra vida educativa nacional, que por momentos llevó a despertar una cierta idea de efervescencia espontánea e incontrolada. En líneas generales podríamos decir que lo que se puso en ejercicio fue una serie bastante matizada de propuestas pedagógicas de carácter fundamentalmente participativas y que tenían como objetivo básico y primordial atacar la tradicional "cátedra" acusada del elitismo, cientificismo, academicismo, espíritu patronal y otros males que se le han enrostrado tantas veces (1998: 117).

\section{Proceso de disciplinamiento}

El 14 de marzo de 1974 se aprobaba la Ley Nro. 20654 Ley Orgánica de las Universidades Nacionales, que reemplazaría la Ley de la dictadura Nro. 17245. Si bien la ley contaba en sus comienzos con el apoyo de los sectores progresistas, una vez aprobada terminaba con las esperanzas que había ocasionado. A esto se le suman una serie de sucesos que comienzan a evidenciar un cambio político: la ofensiva conservadora. Molina Galarza (2014) dice al respecto: 
La sanción de esa nueva ley, en marzo de 1974, muy alejada de las esperanzas de los sectores más radicalizados en las universidades; el distanciamiento de Perón del ala joven y combativa de sus filas, evidenciado en el discurso del 1 de mayo del mismo año; la posterior muerte del líder el 1 de julio, y la llegada de Oscar Ivanissevich al Ministerio de Cultura y Educación de la Nación serían algunos de los acontecimientos públicamente conocidos a través de los cuales se fue reconfigurando el escenario político a nivel nacional (p. 102).

En reemplazo de Jorge Taiana es nombrado como Ministro de Cultura y Educación el doctor Oscar Ivanissevich, el encargado de llevar adelante las reformas conservadoras que se conocieron como Misión Ivanissevich. La Misión tenía por objetivo eliminar el "desorden" en las universidades del país y producir una "depuración ideológica", eliminando no solo lo que consideraba subversión del orden occidental y cristiano sino también todo tipo de participación política (Izaguirre, 2011).

Es en ese marco donde se comenzaban a ensayar varias de las acciones que se convirtieron en política de Estado desde marzo de 1976: expulsiones a docentes y estudiantes, persecuciones, censura, entre otras. Para llevar adelante dicha misión se intervinieron todas las universidades nacionales. En esta línea, por ejemplo, el 25 de enero de 1975 se hace cargo de la UNCuyo Otto Hebert Burgos, que comienza una gestión con renovado gabinete y en consonancia con lo que sucede a nivel nacional.

Ivanissevich ocupará el cargo de ministro durante casi un año, hasta el 11 de agosto de 1975; luego será reemplazado por Pedro José Arrigui. Burgos, en cambio, se mantendrá en el rectorado hasta llegado el golpe de Estado en marzo de 1976. Esta política represiva que ya es evidente en la universidad (como también así en los demás ámbitos de la sociedad) irá creciendo hasta llegar a convertirse en política de Estado en 1976.

Seguimos a Daniel Feierstein (2014) quien entiende que lo sucedido en el periodo abordado fue un genocidio, ya que la dictadura se propuso la destrucción de los grupos y no sólo de los individuos que lo integran. Su objetivo final radica en la destrucción de la identidad del grupo, para imponer la identidad del opresor. Partiendo de esta idea, será clave también para esta investigación el término de práctica social genocida, considerando que "una práctica social implica un proceso llevado a cabo por seres humanos y requiere de modos de entrenamiento, perfeccionamiento, legitimación y consenso que difieren de una práctica automática o espontanea" (Feierstein, 2014: 35-36). Su objetivo radica en "la destrucción de las relaciones sociales de autonomía y cooperación y de la identidad de una sociedad, por medio del 
aniquilamiento" (Ibídem: 83). Para el autor esta práctica fue implementada en nuestro país desde años anteriores al golpe de Estado de 1976.

\section{Cobertura periodística de Los Andes sobre el movimiento estudiantil a partir del 24 de marzo de 1976}

Si bien sostenemos que el genocidio comienza antes de instalada la dictadura, es preciso recordar que solo abordaremos la cobertura realizada por el periódico una vez instalado el gobierno de facto. A los fines de este estudio es preciso aclarar que se ha observado una ruptura, a partir del 24 de marzo de 1976, en la cobertura que realiza el diario sobre la represión ilegal. Para Rodríguez Agüero, la cobertura de la represión previa al golpe pudo desarrollarse por el rol clave de Antonio Di Benedetto y de otros periodistas del diario, como Morán y Bonnardel, que desobedecieron las órdenes policiales y militares. Hay una vasta variedad de noticias que relatan diversos sucesos de la represión ilegal, el diario Los Andes era un lugar de denuncia para familiares de desaparecidos (Rodríguez Agüero, 2014). Pero esta difusión de los hechos termina una vez instalado el golpe: "La madrugada del 24 de marzo el escritor [Di Benedetto] y Morán fueron detenidos en la redacción de Los Andes y llevados al Liceo Militar. A partir de ese momento, las noticias sobre secuestros y desapariciones no volvieron a ser publicadas" (Rodríguez Agüero, 2014: 129).

El 24 de marzo de 1976 comienza la dictadura cívico-militar más sangrienta de la historia reciente de nuestro país. Empieza así un proceso donde las políticas represivas que se venían ensayando se agudizan, donde el terror es sistematizado y ejercido por el Estado. Entre las medidas llevadas adelante para "combatir la subversión", se dispone la intervención de las instituciones públicas. Universidades, facultades y escuelas debían estar bajo la órbita militar, implementar sus lógicas.

Una vez instalada la dictadura se insiste de manera permanente en criticar el periodo democrático, catalogarlo de anárquico, inestable, desordenado, ente otras. En relación con esto, en las universidades se hace hincapié en el proceso iniciado en 1973. Los juicios a docentes y el ingreso irrestricto se encuentran entre las acciones más criticadas. Lo sucedido en esos años es demonizado, utilizado como ejemplo de lo que "nunca más" debe suceder. Vemos ejemplos de la Escuela de Servicio Social, la Universidad del Sur y una reunión de rectores con el entonces Ministro de Educación Bruera: 
Desde octubre de 1973, un grupo de profesores, que no representaba a la mayoría, uniéndose a los estudiantes de ideología marxista, alentó la constitución de asambleas estudiantiles que se constituían a diario, y en las cuales se llegó a enjuiciar a profesores y alumnos caracterizados por su tendencia democrática, con amenazas posteriormente a los mismos (Los Andes, 3 de agosto de 1976: 6).

\begin{abstract}
Al hacerse la intervención militar, encontró a la Escuela en crítica situación. A partir de junio de 1973 se produce la toma de la Escuela como consecuencia de una asamblea realizada con participación de un grupo de profesores y alumnos. Se producen desmanes y se inicia la reforma del Plan de Estudios (Los Andes, 5 de agosto de 1976:4).
\end{abstract}

A partir del 24 de marzo y con la instauración de la Junta Militar en el Gobierno, se sostuvo que el llamado ingreso irrestricto universitario había producido, además de una deformación en la enseñanza superior argentina, una importante infiltración ideológica en las aulas (Los Andes, 12 de octubre de 1976: 1).

El 24 de marzo, el Comodoro Héctor Ruiz había sido designado Rector interventor de la UNCuyo (2). Ruiz fue el encargado de profundizar hasta sus máximos niveles las políticas iniciadas por la denominada Misión Ivanissevich: expulsión y cesantías a miembros de la comunidad universitaria, el cierre de carreras, la censura. Durante su mandato cerca de doscientos trabajadores fueron dados de baja, trescientos estudiantes fueron expulsados y más de treinta personas de la comunidad universitaria de la UNCuyo fueron desaparecidas y/o asesinadas. Estas políticas se repiten en las demás escuelas y facultades provinciales. Respecto al cierre de carreras, en la UNCuyo fue cerrada la carrera de Sociología de la Facultad de Ciencias Políticas y Sociales. Fueron cerradas las Facultades de Antropología Escolar-FAE-, Comunicación Colectiva, Turismo y Servicio Social (dependientes de la Dirección General de Enseñanza de la provincia de Mendoza) y sus careras, transferidas. A la UNCuyo, se transfirieron todas las carreras de la FAE menos Psicología, que pasó a la Universidad del Aconcagua. A la Universidad Juan Agustín Maza se transfirió la carrera de Comunicación Colectiva, y a la Universidad Católica de Cuyo, la carrera de Turismo (Baigorria, 2014).

Los datos de la represión a estudiantes no aparecen en Los Andes. El periódico solo cubre las acciones de los militares y son sus discursos los que tienen lugar en las páginas del diario. Es lo que Van Dijk (1999) denomina "abuso del control sobre el discurso"; esto es utilizado para orientar las creencias y acciones en interés de los grupos dominantes, en este caso, la dictadura y los sectores económicos que la apoyan. 
Hay un dato que se observa en el periódico, los datos de la censura, la persecución ideológica y el autoritarismo. En una nota titulada "Cerca de 10.000 publicaciones extremistas hallaron en la UNC", a través de las palabras del periodista se detalla la visita que realizaba la prensa a la sala de sesiones de la Universidad Nacional de Cuyo. En la fotografía que ilustra la noticia se observan expuestos una gran cantidad de libros y afirmaciones como la siguiente: "Se había reunido una abundante cantidad de libros, apuntes, afiches, todos de neto corte comunista" (Los Andes, 8 setiembre 1976: 5). Continua la nota: "ese material, en su totalidad de propaganda de izquierda, fue retirado del lugar donde se encontraba, entre el 24 de marzo y 4 de abril, día en que comenzaron las clases" (Ibidem). El mensaje es evidente, lo que se considera peligroso, es rastreado, encontrado y apartado. 


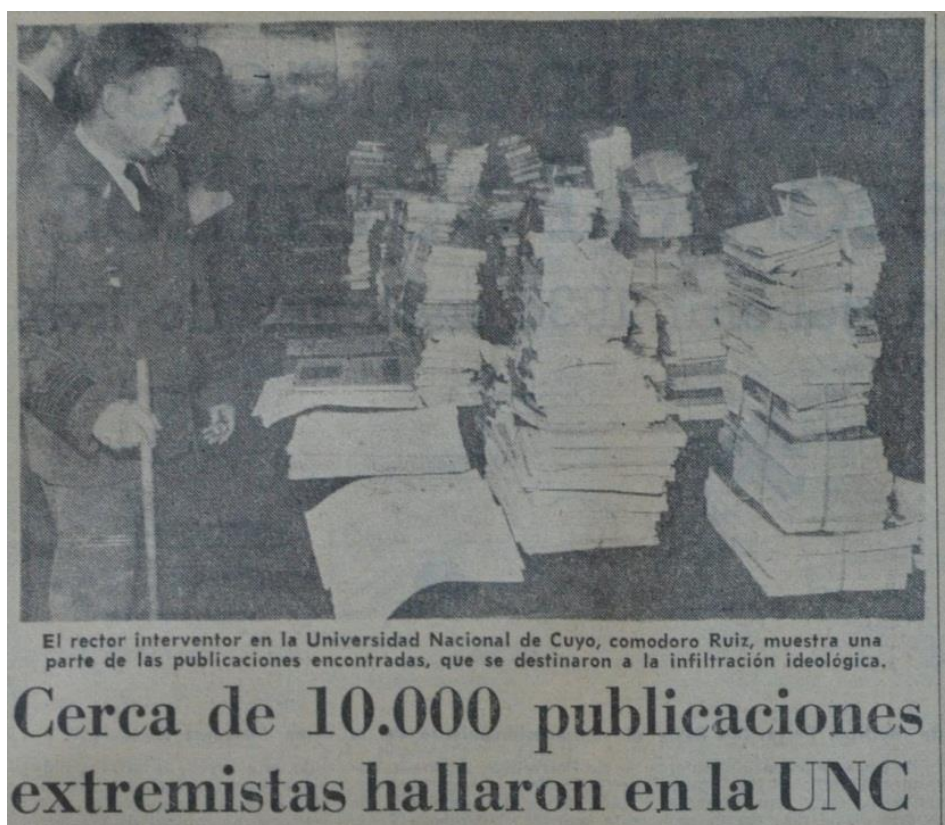

\section{Señalóse origen trotskista del "sistema de áreas"}

La infiltración ideológica en la Uni- | Universidad Nacional de Cuyo. El comoversidad, en el periodo 1973-75, los cursos doro ingeniero Héctor Eduardo Ruiz, preuniversitarios y graves irregularidades mostró en la ocasión abundante material administrativas durante la gestión del bibliográfico extremista encontrado en ex rector Otto Burgos, fueron los temas $\quad$ las distintas facultades y escuelas depenque abordó ayer, durante una conferen-
cia de prensa, el rector interventor en la

Previo a la conferencia cou figuran también banderas de tor Silva Michelena y Heinz os periodistas, el com odoro
organizaciones ceclaradas fueRuiz invito a los hombsiones numero 1, como io expresó el eran: Revolución universitaria del rectorado, donde se habia rector, de la cesantia de yarios que se trasiacia luego a toda la - prolesores y la expulsion tidad de libros, apuntes y a munista. Ell material bibliográfico exhibidio estaba compuesto por un tomo o colecda en las distintas facultades, y escuelas de la universtorios utilizados por alguno fesores o e st udiantes. E material, unos 10.000 se encuentra archivado $y$ otros vicios de inteligencia de Fuerza Aérea. Ese material, en su totalidad de propaganda gar donde se encontraba, entre el 24 de marzo y el 4 ca abril dia
las clases.

En cuanto al origen de $\epsilon$ sas comodoro Ruiz manifestó que en parte han sido adquirida con fondos de la an su mayoria del sistema de can que se mantenia con la Un versidad Central del Ecuedar. Anadio que tistas publicacioA esta altura de $1 \mathrm{a}$ expositangibie para la accion inme(181 "hombre nuevo" (condicionaco protesores sancionados y en a la teoria marxista, ecentes. En cuanto a los es- tor, se logra: disociación y caos tes, manifestó que han en el ambito universitario; se sido expulsados 114 y suspen-
observa en cronologia de heprimeros destacó que los menos ban sido san
falta de idoneidad

"Sistema de áreas" \begin{tabular}{l|l} 
taciones, etc.; recrudecian mo- \\
vimientos estudiantiles, aliados \\
a huelgas obren
\end{tabular} Tras exhir el material im- 1972 , coincidentemente con preso utilizado para la infi- campaña electoral, y en tración comunista en la Universidad, ei comodoro Ruiz ps- laban la conducción de gobierguió su exposición. En primer armadas y de seguridad. Este "sistema" agrego, se im-
érmino mostró una coleccion de discos con pro jaganda co- plantón unque se desconoce su remi- incluso pasó a estabiecimientas \begin{tabular}{|l|l|l|} 
ente. Enseguida pasó a mani- & dependientes de ia provincia. \\
De tal manera Cuyo se cons-
\end{tabular} festar que "la organizacion que - tituyó, dijo. en el principal persidad descie 1973 a fines de centro estudiantil do nde so 1975 fue el denominado "Sis- aplicó et sistema "sin estruenpubicación mexicana "Univer- sus principlos,

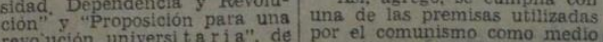

Figura 1: Artículo del diario Los Andes, 8 de setiembre de 1976: 5. 
A través de las palabras de Ruiz se defiende que la "subversión estudiantil", aliada de la "peligrosa clase obrera", fue la ejecutora del caos que, según ellos, reinó en las universidades a partir de la gestión de Taiana como Ministro de Cultura y Educación. La apuesta por instalar la idea de desorden, que se observa también en otros ejemplos, es muy clara aquí:

\begin{abstract}
Disociación y caos universitario; se observa en cronologías de hechos subversivos estudiantiles, insurrección, cuestionamiento, toma de facultades, manifestaciones, etc.; recrudecían movimientos estudiantiles, aliados a huelgas obreras, y en "unión" desprestigiaban y burlaban la conducción de gobierno y la acción de las fuerzas armadas y de seguridad (Los Andes, 8 de setiembre de 1976: 5).
\end{abstract}

Borrelli (2010) en su análisis sobre el diario Convicción hace referencia a la idea de que el país estaba inmerso en el "caos", situación que termina por la actuación de los militares:

\begin{abstract}
El único actor no "contaminado" por la fragilidad institucional de la etapa democrática eran las Fuerzas Armadas, quienes con su acción palingenésica le devolverían su fortaleza a las instituciones. Se establecía así una suerte de división maniquea en bandos donde los militares pertenecían al lado positivo como actores pasivos de la historia argentina, llamados a actuar por la "inevitabilidad" de los acontecimientos. En esa interpretación, el golpe de 1976 había salvado al país, y el proceso histórico abierto por la dictadura militar constituía una etapa de reparación y reconstrucción que daría nacimiento a una democracia moderna y estable (p. 62).
\end{abstract}

La Universidad debía dejar de ser un "centro de propagación de marxistas", para ello había que prohibir y sancionar severamente todo tipo de participación. Bajo el título "El gobierno modificó la ley universitaria" el diario dice: "Prohíbe expresamente en el recinto de las universidades, toda actividad que consumo formas de adoctrinamiento, propaganda, proselitismo o agitación de carácter político o gremial, docente, estudiantil y no docente" (Los Andes, 2 de abril de 1976: 1). Las universidades, que habían sido cooptadas por las organizaciones de izquierda, debían aplicar para si el "plan de exterminio de la "subversión". Alberto Constantini, quien fuera el Rector de la UBA, en su renuncia dice:

Debo reiterar, señor ministro, mi convicción profunda de que la universidad no debe permanecer ajena a la lucha que las Fuerzas Armadas Ilevan adelante contra la subversión, pero su contribución no puede ser otra que acudir a sus propias armas, que son las 
académicas, preparando profesionales e investigadores para el país y ciudadanos de la república (Los Andes, 14 de setiembre de 1976: 1).

La identidad que construye el diario Los Andes de la juventud y los/as estudiantes, eligiendo las palabras y discursos de quiénes instalar y cuáles silenciar, tiene que ver con características y descripciones basadas en conceptos tales como: delincuencia subversiva, terrorismo, extremistas, entre otras. Los y las estudiantes con inquietudes políticas son portadores de estas características. La polarización del nosotros (el pueblo argentino) y del ellos (los delincuentes subversivos) (Van Dijk, 1999) es evidente y está presente de forma permanente. En una nota titulada "Se alertó sobre infiltración extremista en la educación" se lee: "El comandante del Primer Cuerpo de Ejército, general Carlos Guillermo Suarez Mason, alertó hoy sobre la infiltración extremista en la educación nacional y dijo que era en ese marco donde se gana la batalla contra la subversión" (Los Andes, 25 de setiembre de 1976: 1). El régimen insiste en que la subversión estaba instalada en las universidades. En ese sentido se expresa la noticia con motivo del inicio del ciclo escolar en la Facultad de Antropología Escolar (FAE) y otra de la Universidad Nacional del Sur:

Durante ese lapso [1973] se instaló en el hall central de la Facultad un quiosco donde se exponía literatura subversiva y funcionó un sistema de altavoces utilizado para transmitir marchas políticas y proclamas con el nombre "Radio Liberación" actuando como locutores alumnos de establecimiento (Los Andes, 3 de agosto de 1976: 6).

[General Vilas:] Los ideólogos -prosiguió- infiltrados en todos los ambientes, envenenan a la juventud desde los claustros universitarios a las aulas secundarias y sino se desenmascara y desbarata a esa maquinaria generadora de delincuentes, la infiltración será total. Agregó que "la izquierda revolucionaria, en sus designios, no encuentra obstáculos en arrollar ideológicamente a una sociedad en forma global con tal de lograr sus propósitos (...)". (Los Andes, 5 de agosto de 1976: 3). 


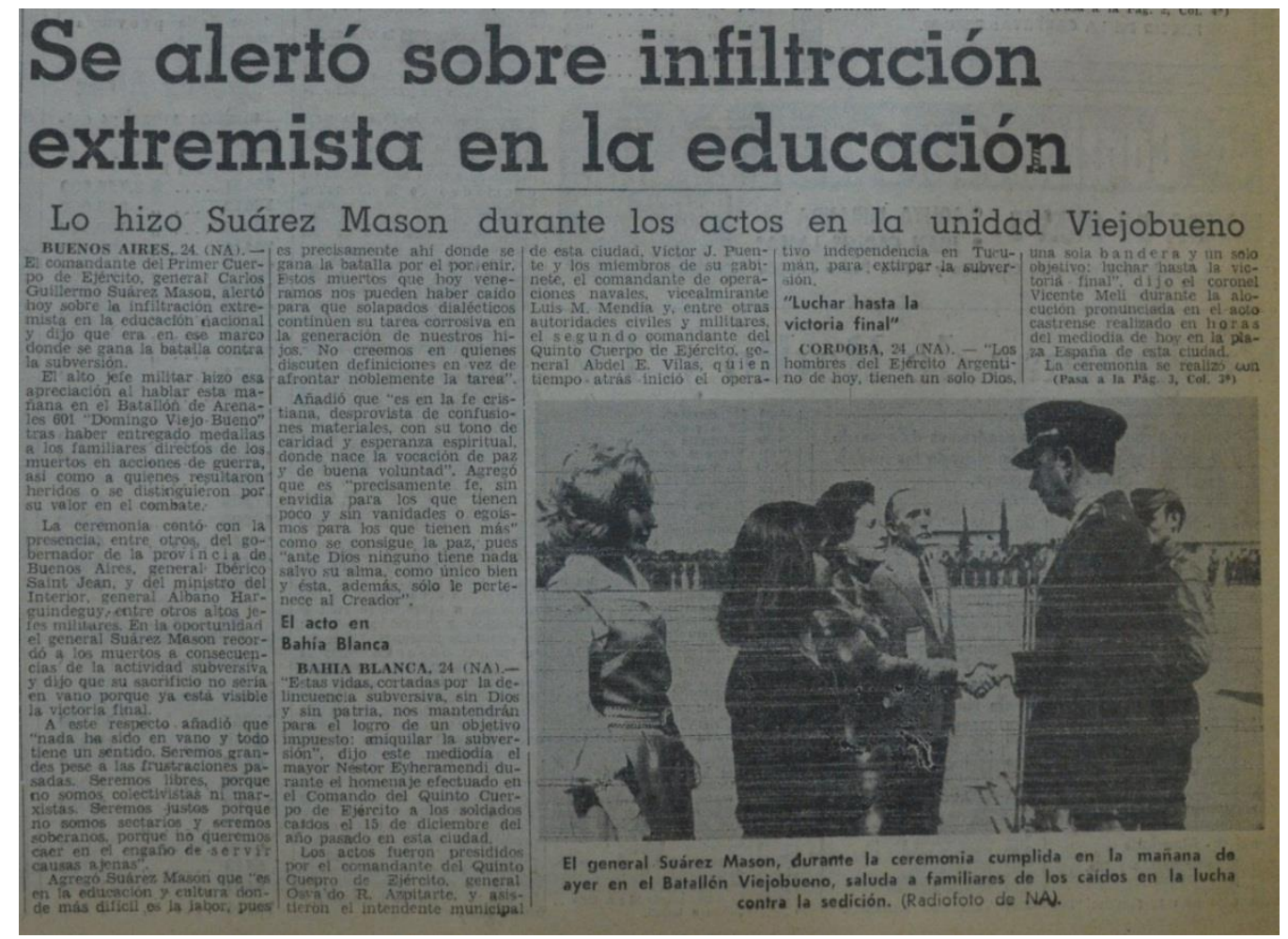

Figura 2: Artículo del diario Los Andes, 25 de setiembre de 1976: 1.

La necesidad de un trabajo de inteligencia para identificar a "los/as enemigos/as", por ejemplo, suele estar implícita en todas las crónicas, pero en ocasiones aparece explicita. En otro fragmento del artículo citado anteriormente sobre la FAE, el Ministerio "resolvió suspender el otorgamiento de certificados habilitantes a los egresados de la Facultad del periodo 1973/76. Es un principio básico de responsabilidad para la sociedad que obliga al análisis de los legajos de todos y cada uno de los egresados" (Los Andes, 3 de agosto de 1976: 6).

Como se ha dicho, para los militares y la prensa lo "subversivo" debe ser combatido hasta sus últimas consecuencias. Las palabras del Interventor de la UNCuyo van en consonancia con esto:

El Comodoro Ruiz agregó que se dictaron normas para sancionar la actividad subversiva, la indisciplina y el proselitismo político. En este sentido dijo que se ha hecho conocer las pautas vigentes para respetar la jerarquía, observar disciplina y decoro dentro del ámbito universitario, y en general se ha exhortado al personal y alumnos a cumplir sus obligaciones específicas (Los Andes, 14 de agosto de 1976: 6). 
Partimos de la idea que los medios de comunicación son espacios que otorgan significación a ciertas prácticas sociales, legitiman posiciones, construyen acontecimientos y representaciones de la realidad; y que además los medios dicen a quién admirar y a quién tener miedo (Orozco Gómez, 1998). En relación con ello, y como ya hemos dicho, vemos cómo se busca construir por una lado a los/as estudiantes y por otro a los militares. Hay un fuerte trabajo por catalogar a la "subversión marxista" como "el enemigo común del pueblo". Entre tanto, los militares buscan establecer el orden, los valores cristianos y occidentales. La "subversión" es caracterizada como disociadora, revoltosa, al servicio del socialismo internacional (y no del pueblo argentino), aliados de la "peligrosa" clase obrera, agitadores, etcétera. Algunos ejemplos de esto:

Los objetivos del sistema [de áreas] eran: Revolución universitaria que se traslada luego a toda sociedad; proveer a las fuerzas de izquierda un programa tangible para la acción inmediata en pro de una revolución universitaria y transformación universitaria de la sociedad toda; echar bases para un "hombre nuevo", condicionado a la teoría marxista. (...). Así, agregó, se cumplía con una de las premisas utilizadas por el comunismo como medio para llegar al poder (Los Andes, 8 de setiembre de 1976: 5).

Situación ideológica detectada: la reforma educativa en Servicio Social respondía a un plan de copamiento de la profesión Asistente Social, vaciamiento de su rol y transformación de la Escuela en centros de adoctrinamientos marxista. (...) Con un grupo de profesores y con el apoyo de una parte de docentes y alumnos de la Escuela, se implementó a partir del seminario de julio de 1973, la practica revolucionaria simbólica a puertas cerradas, con intenso adiestramiento mediante técnica de dinámica grupal. Así la Escuela Superior de Servicio Social fue un centro de formación de activistas políticos-sociales, en el que se inculcaba permanentemente traición a nuestro ser nacional, traición a Argentina y los valores cristianos que nos dan fisonomía como país (Los Andes, 5 de agosto de 1976: 4). 


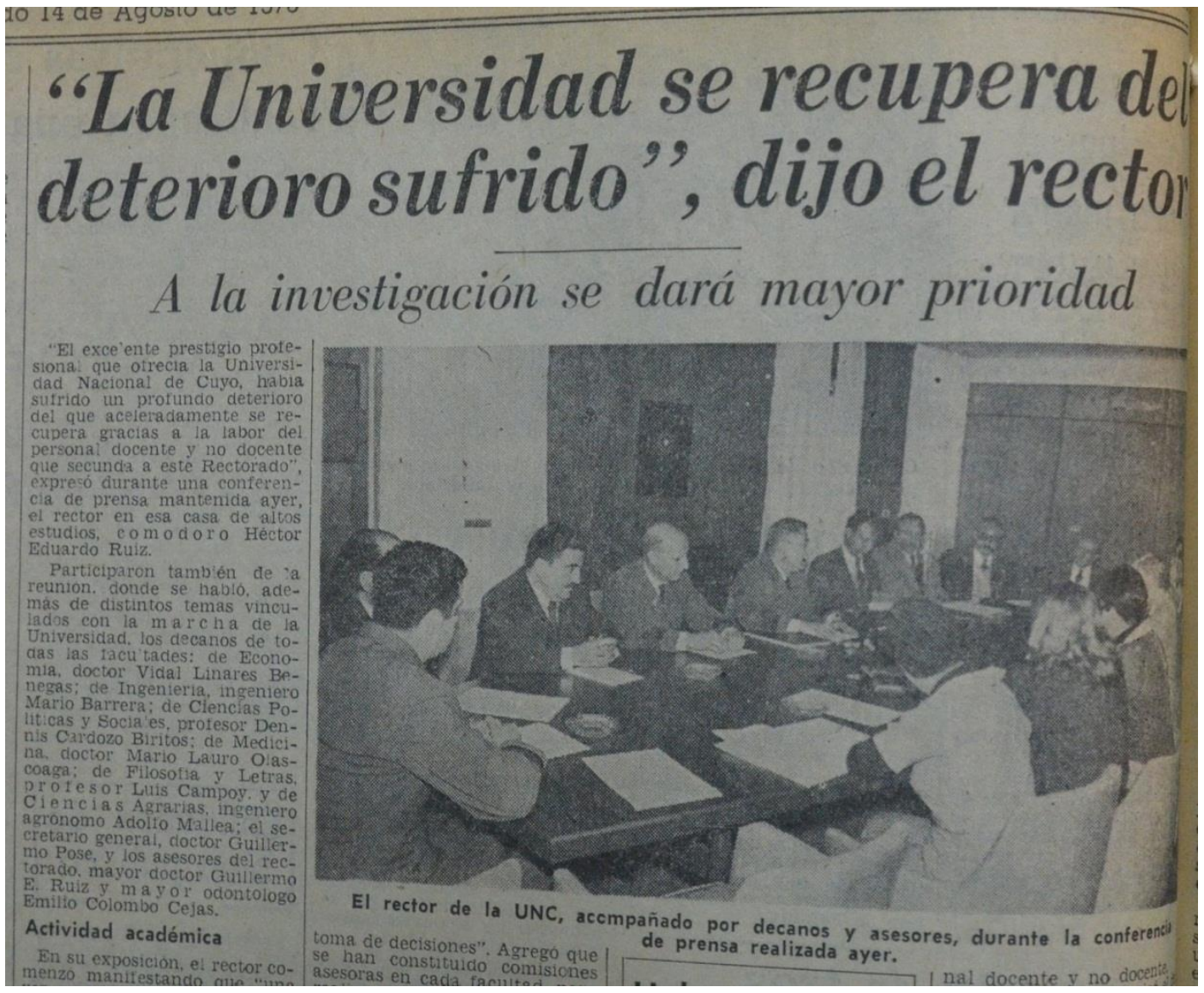

Figura 3. Artículo del diario Los Andes, 14 de agosto de 1976: 6.

Por otro lado, la identidad mediática que se construye sobre de las fuerzas de seguridad es radicalmente distinta a la de los/as jóvenes-estudiantes. Son ellos los que tienen el poder moral y material para "luchar contra la subversión". Su identidad y su accionar represivo no son cuestionados por el medio gráfico. Sampedro (2004) sostiene: "ciertos grupos sociales no sólo gozan de favores mediáticos, sino que la imagen que proyectan los medios les blinda de cualquier identificación que ponga en duda su status" (p. 137). Tal es el caso del rol que jugó el diario Los Andes con esta construcción, vemos esto en la cita de las palabras del rector interventor Comodoro Ruiz. Se observa, nuevamente, la idea de que son los militares "los encargados de ordenar el país", de "sacarlo del caos". El diario mendocino resalta la "gran tarea" de los militares locales, al haberse convertido en los primeros del país en "regularizar" la situación universitaria: 
El excelente prestigio que había tenido la Universidad Nacional de Cuyo, había sufrido un profundo deterioro del que aceleradamente se recupera". (...) "una vez asumidas las funciones por el nuevo delegado militar y su equipo, se encargó la tarea de regularizar la actividad de las Facultades en Institutos de la Universidad, objetivo que se alcanzó a los diez días, siendo la primera Universidad Nacional que logro normalizar en dicho aspecto (Los Andes, 14 de agosto de 1976: 6).

En el capítulo Represión y prensa gráfica en Córdoba, Ponza y Soaje afirman que la última dictadura militar puso en práctica un plan de comunicación social centralizado que buscaba marcar la agenda informativa de los medios de comunicación, para generar una sensación de consenso interno. Los autores afirman que:

En consonancia con dicho plan, era imprescindible que la prensa gráfica -sea esta de alcance nacional o regional- colaborara en la recreación ficticia de un clima de normalidad y orden, estableciendo un blindaje mediático que ocultara las violaciones de los derechos humanos que cotidianamente cometían los Grupos de Tareas (Ponza y Soaje, 2016: 144).

En ese sentido, podría decirse que los medios masivos de comunicación, en tanto mediadores de la realidad, fueron utilizados por el gobierno de facto. La ideología del régimen era difundida masivamente por los medios, al mismo tiempo que se ocultaron graves violaciones a los derechos humanos y se censuraron voces disidentes.

\section{Conclusión}

Es preciso retomar algunos datos que tienen relación con la ruptura en la cobertura de las noticias sobre la represión ilegal a partir de la última dictadura militar, mencionada por Rodríguez Agüero (2014). Una vez instalado el golpe de Estado solo aparecen diez noticias relacionadas con lo estudiantil, desde marzo a diciembre de 1976, reducción abrupta comparada con el periodo previo. Las crónicas tienen que ver con cambios en las políticas estudiantiles, el secuestro de "material subversivo" de las instituciones educativas, la "depuración ideológica" o el "saneamiento" de las universidades. En cambio, por ejemplo, en 
ninguna de estas noticias se relata o menciona la desaparición, secuestro y asesinatos de estudiantes y docentes y mucho menos se toma en cuenta su versión de los hechos.

Una de las hipótesis centrales sostenía que la prensa local utilizó el mismo lenguaje que la dictadura, lo que implicó la legitimación del discurso oficial respecto a la lucha contra la subversión y el establecimiento del orden. En este sentido decimos que el diario escoge que voces reproducir y cuales silenciar. En ninguna noticia se cita a los y las estudiantes que han sufrido las políticas de la represión. En todos los casos son las voces oficiales las citadas por el periódico. Su estrategia es reproducir textualmente las palabras de los militares o sus comunicados. En ningún caso son introducidas citas disidentes con esas posiciones.

El Análisis Crítico del Discurso (ACD), aplicado aquí en las crónicas de Los Andes durante el periodo abordado, permite demostrar "el modo en que el abuso del poder social, el dominio y la desigualdad son practicados, reproducidos (...) por los textos y el habla en el contexto social y político" (Van Dijk, 1999: 23). Al analizar las noticias del diario puede observarse cómo este reproduce textualmente comunicados militares y, como ya se dijo, siempre se refleja la versión oficial de los hechos y en ningún caso aparecen las versiones de las víctimas. Además sobre estas últimas, habrá un gran trabajo de desprestigio y demonización. De esta forma, busca despojarlas de características humanas para poder así justificar los graves delitos cometidos contra ellas. Las crónicas analizadas ponen en evidencia cómo la práctica periodística se convirtió en una herramienta fundamental para defender, justificar y avalar el genocidio.

En ese sentido, fue confirmada la hipótesis que afirmaba que el diario colaboró en crear un imaginario de desastre y violencia donde el establecimiento del orden debía ser inminente. Los militares debían terminar con las y los "enemigos del pueblo", entre ellos la "subversión estudiantil". Sobre la construcción de un clima de caos, se observa la necesidad de establecer el "orden" como una idea constante en las notas de Los Andes. Se busca construir un consenso sobre la "necesidad de acabar con el desorden". Esto se elabora caracterizando el periodo democrático anterior como un proceso de caos y anarquía, donde la autoridad no era respetada y donde los valores occidentales y cristianos estaban en peligro por las acciones de la "subversión marxista".

Constantemente se alude a las conquistas del movimiento estudiantil, en materia de planes de estudio por ejemplo, como productoras del caos universitario, del desorden que llevó a la universidad al desprestigio y al desastre total. Ante esto se crea "la necesidad de sanear el ambiente" y con ello revertir la situación, donde toda medida adoptada (expulsiones, persecuciones, etcétera) es necesaria. Son los militares los encargados de llevar adelante "la noble tarea" de recuperar los "valores perdidos", de "encaminar el país". En ese contexto, todas 
las medidas utilizadas para acabar con el desorden y la anarquía institucional y nacional quedan justificadas. En ese sentido Borrelli (2010) dice:

\begin{abstract}
Se consideraba "la lucha contra la subversión" como una guerra excepcional que merecía una respuesta también excepcional por parte del Estado. No podían calificarse de "excesos" las acciones en esa lucha debido a que las Fuerzas Armadas habían librado una guerra fuera de lo común. Los militares habían actuado para salvaguardar la Nación contra el ataque de los "grupos terroristas" que unilateralmente habían iniciado la conflagración, por ende eran tan víctimas como los ciudadanos (p. 62).
\end{abstract}

El periódico reproduce una idea constante en los discursos militares: mostrar urgente la necesidad de revertir todo lo gestado en 1973. Esto es cambiar el sistema de áreas, devolver el prestigio a las autoridades, retornar al viejo sistemas de evaluaciones y a los cupos de ingreso en las facultades, terminar definitivamente con el "centro de formación marxista" en el que se habían convertido la universidad, las escuelas y las facultades provinciales. Este orden era posible y lo fue "de la mano de los militares".

Esta idea de que el caos y la anarquía institucional fueron posibles por las acciones del movimiento estudiantil tenía su explicación más fuerte en la elaboración de dos identidades opuestas: estudiantes subversivos versus fuerzas de seguridad salvadoras. Con ello se confirma la hipótesis que sostenía que Los Andes promovió construcciones discursivas en las que se atribuían características negativas a los y las estudiantes, asociadas con las palabras subversión, terroristas, delincuencia, apátridos, entre otras. A su vez asoció características y acciones positivas para los integrantes de las Fuerzas Armadas, como por ejemplo atribuirle la tarea de ordenar al país en base a "valores democráticos, cristianos y occidentales".

Los Andes es el medio de comunicación gráfico más antiguo de la provincia de Mendoza. Como todo medio, difundió masivamente noticias sobre lo que sucedía en nuestro país, esto lo hizo utilizando el mismo lenguaje que la dictadura: reproduciendo textualmente sus comunicados y dando lugar solo a las voces oficiales. Sus crónicas, en consonancia total con los intereses del gobierno de facto, se orientaron a crear construcciones donde los y las estudiantes fueron fuertemente atacados, criminalizados y culpados como "provocadores del desorden y caos" en que se había convertido la universidad y el país. Esto genera, por un lado, la estigmatización de toda la juventud universitaria, y de la juventud en general. Por otro, busca elaborar una idea general de consenso: los militares debían "cortar este mal de raíz", imponer el "orden" aunque sea asesinando y desapareciendo. El genocidio queda justificado. 


\section{Notas}

(1) En los denominados "juicios académicos" profesores y autoridades eran interpeladas por mal desempeño (según el estudiantado), tanto académicamente (contenidos de la materia, forma de evaluar, etcétera) como éticamente (apoyo o actitud participativa en las dictaduras precedentes). Dos de los más resonantes se llevaron a cabo contra Dardo Pérez Gilhou, quien fuera Ministro de Educación de Onganía (1969-1970) y por ello responsable de la Reforma Educativa impulsada por la dictadura, y Héctor Gómez Rueda (responsable de la represión en el departamento de Las Heras durante el Mendozazo) (Baigorria, 2014).

(2) Ruiz se mantuvo en el puesto hasta el 3 de setiembre de 1976, cuando asume Pedro Santos Martínez. A este último le sucedió Enrique Zuleta Álvarez, quien fue designado en 1981 y se mantuvo hasta la finalización de la dictadura. Si bien las políticas de represión y censura son implementadas por el primer rector, las mismas son mantenidas por las autoridades siguientes.

\section{Bibliografía}

Baigorria, P. (2014). La construcción mediática del movimiento estudiantil mendocino: periodo 1970-1976. Caso diario Los Andes. (Tesis de grado). Facultad de Ciencias Políticas y Sociales, UNCuyo, Mendoza.

Borrelli, M. y Saborido, J. (2010). "El diario de Massera”: convicción durante la dictadura militar. Revisión del artículo La prensa del 'Proceso'. El diario Convicción durante la dictadura militar argentina (1976-1983) (2008). Estudios sobre el mensaje periodístico, 14, pp. 49-78, Universidad Complutense de Madrid, Madrid.

Bravo, N. (2014). Experiencias y prácticas políticas del movimiento estudiantil de Mendoza entre 1970 y 1973. En Bravo, N.; Molina Galarza, M.; Baigorria, P. y Tealdi, E. Apuntes de la memoria. Política, reforma y represión en la Universidad Nacional de Cuyo en la década del 70 (pp. 22-53). Mendoza: EDIUNC.

Diario Los Andes. 24 de marzo de 1976 al 31 de diciembre de 1976, Mendoza.

Feierstein, D. (2014). El genocidio como práctica social. Entre el nazismo y la experiencia argentina. Buenos Aires: Fondo de Cultura Económica.

Izaguirre, I. (2011). La Universidad y el Estado Terrorista. La Misión Ivanissevich. Conflicto Social, 4(5), 287-303.

Molina Galarza, M. (2014). Transformaciones político-pedagógicas y terrorismo de Estado en la Universidad Nacional de Cuyo. En Bravo, N.; Molina Galarza, M.; Baigorria, P. y Tealdi, 
E. Apuntes de la memoria. Política, reforma y represión en la Universidad Nacional de Cuyo en la década del 70 (pp. 86-115). Mendoza: EDIUNC.

Fernández Nadal, E. (2001). Revolución y utopía: Francisco de Miranda y la independencia hispanoamericana. Mendoza: EDIUNC.

Orozco Gómez, G. (1998). De las mediaciones a los medios. Contribuciones de la obra de Martín-Barbero al estudio de los medios y sus procesos de recepción. En Laverde, M. C. y Reguillo, R. (eds.). Mapas Nocturnos. Diálogos con la obra de Jesús Martín Barbero (pp. 91-101). Bogotá: Siglo del Hombre Editores.

Ponza, P. y Soaje, J. (2016). Represión y prensa gráfica en Córdoba. En Solis, A. y Ponza, P. (comps.). Córdoba a 40 años del Golpe: estudios de la dictadura en clave local (pp. 123-148). Córdoba: Universidad Nacional de Córdoba.

Roig, A. (1998). La Universidad hacia la Democracia. Bases doctrinarias e históricas para la constitución de una pedagogía participativa. Mendoza: EDIUNC.

Rodríguez Agüero, L. (2014). El diario Los Andes y el combate contra la "subversión" en la Mendoza pre y postdictatorial (1975-1978). En Red de Historia de los Medios. Televisión, Dictadura y Transición en Argentina (Dossier), 7, pp. 119-143.

Sampedro Blanco, V. (2004). Identidades mediáticas e identificaciones mediatizadas. Visibilidad y reconocimiento identitario en los medios de comunicación. CIDOB d'afersinternacionals, 66-67, pp. 135 -149.

Van Dijk, T. (setiembre-octubre, 1999). El análisis crítico del discurso. En Anthropos, 186, pp. 23-36. 